\title{
Replacing Plastic: An Assessment of New Material for Food Production Package to Re-Engineer Packaging Industry Based on Multi-Criteria Analyses
}

\author{
Dikky Indrawan \\ School of Business \\ IPB University (Bogor Agricultural University) \\ Bogor, Indonesia \\ rdikky@ apps.ipb.ac.id
}

\author{
Stevia Septiani * \\ Department of Management \\ IPB University (Bogor Agricultural University) \\ Bogor, Indonesia \\ steviaseptiani@apps.ipb.ac.id
}

\begin{abstract}
Decisions in relation to planned food package materials to reduce and replace plastic materials are made in the initial phase of investments. Different alternatives of packaging resources and materials are assessed, which requires reviewing many factors. As there many factors are considered, the more challenging to reach a decision. The decision-making method can be performed with a variety of approaches to analyze alternative material solutions related to its manufacturing process, re- engineering and industrial revolution 4.0. One approach is to use a multi-criteria decision analysis method. The methods focused on factors and problem that linked with alternative materials for analyses. Based on AHP methods shows that the main criteria that support the goal to select the new material for food packaging is environmental friendly (0.31760). Palm leaves is the priority choice for ecofriendly bio-based food packaging (0.11242).
\end{abstract}

Keywords: food packaging, innovation, replacing plastic, sustainable design, analytical hierarchy process

\section{INTRODUCTION}

As the environmental issue getting more attention, food plastic package is under pressure to be reduced and replaced. As the battle against plastic waste increases, many industries seek plastic alternatives and sources [1][2]. Since the current source of food packaging still relies on the plastic materials. Producers has to decide the future plan concerning the investments to replace plastic food package completely from the manufacturing process. The plan needs strategic decisions regarding alternative food package materials. Therefore, different alternatives of packaging solutions and materials need an evaluation and it requires reviewing many factors such as the quality and durability of the new material and the cost of technology investment. Definitely, if there many factors are considered to find sustainable and environmental-friendly food packaging materials, the more challenges to reach a decision.

Finding sustainable food packaging material is the fundamental discussion in the context of company decision and investment choices. The main concern is that the new material should be ecological fitted, socially accepted and economically suitable for the investments
[3]. The decision-making process can be performed with a variety of approaches to analyze alternative material solutions related to its manufacturing process, reengineering and industrial revolution 4.0 [4][5]. Analytical Hierarchy Process (AHP) as multi-criteria methods are useful for efficient decision making due to a large number of factors that need to be considered. This paper objective is to assess the most suitable new material for manufacturing to fabricate a food packaging based on multiple factors by using AHP.

\section{MATERIALS AND METHODS}

\section{A. Data collection}

In this initial study, we obtained the data set from structural interviews the experts and practitioners who are familiar and have a knowledge on new alternative materials. In total, there were 5 experts from plant science, food science and social science who were agree to be part of this initial study. In addition, the research data collected data via literature review from books, government reports, and scientific articles.

\section{B. The AHP steps}

We employed AHP as the main assessment tool to define the decision that will be applied on evaluation of all new food packaging material variants. AHP as a multi-criteria decision analysis method was introduced by [6]. The methods focused on factors and problem that linked with alternative materials for analyses. The AHP was performed in sequential steps as follows:

1. Define selection objective goal

2. Form elements in criteria, sub-criteria, alternatives in hierarchy

3. Construct pair-wise comparison of elements in each group with respect to the objective

4. Calculate weight and consistency index at all level. As a note, the consistency ratio (CR) should not be above 0.1 or $10 \%$

5. Assess and evaluate priority based on weight

6. Choose the best alternatives 


\section{AHP framework to choose the new material for food production package}

The AHP framework was set the new material for food package as the ultimate goal. To determine the goal, it is essential to choose the criteria for the new material for food package. We selected the criteria based on literature review and expert interviews. There were five criteria as the main determinant to select the suitable material as follows:
1. Quality
2. Cost of material
3. Cost of new investment
4. Cost of human resource training
5. Environmental friendly

There were 13 alternative materials that were evaluated based on these criteria, as shown in Fig 1. The materials were as follows:

1. Plant-based plastics. This material is also known as bioplastics that are made from a variety of sources such as corn. The material is broken down into PLA, or polylactic acid.

2. Mushroom root. This material is developed with mycelium.

3. Bagasse. The material comes as a by-product of sugarcane processing. The material could be mold into packaging material as similar to polystyrene but biodegradable and compostable.

4. Seaweed water bubbles.

5. Shower-friendly paper. The paper material consists of recyclable plastic but has $60 \%$ less material than regular plastic bottles.

6. Stone paper and plastic. The paper has a lower carbon footprint. Paper is made from calcium carbonate, as it is abundant resources and its production requires less water. The manufacturing process is energy efficient.

7. Palm leaves. The leaves are from areca palm that molded into the desired different form.

8. Corn starch and sorghum loose fill. The material is made from corn starch or sorghum. The material is similar as regular polystyrene loose fill.

9. Edible six-pack ring. The material is from barley and wheat remnants that comes as a by- product of the brewing process.

10. Silber board - metallized paper. The material is Developed as a sustainable alternative to traditional composite metallized papers and boards.

11. Wood pulp cellophane. The material is made from FSC certified wood pulp that biodegradable.

12. Prawn shell plastic bags. The material is chitosan, which is made from prawn and crab shells.

13. Milk plastic. The material is come from Casein - the protein found in milk. It has been used to make plastic but less prefer than petrochemical.

\section{RESULTS}

This section presents results with a data analysis by AHP and its interpretation. Table 1 shows that the main criteria that support the goal to select the new material for food packaging is environmental friendly. The next essential criteria are cost material and quality. These three criteria had the higher value compare to others which meant it determined the alternatives.

As we already know, the impact of using plastic packaging is very detrimental to the environment due to their non-biodegradability (it can take up to 500 years for the material to decompose). Plastic litter results in high waste management costs, damages the marine ecosystems, even enters into our food chain due to the effect of bioaccumulation, which affects public health [7][8]. Ecofriendly food packaging is an alternative solution for the sustainability of future lives.

Based on the priority ranking, we found out that related plant based materials were in the higher ranking based on these three criteria. Palm leaves was selected as the best alternative out of 13 possible materials for food package alternatives. It was followed by plant based plastics and corn starch and sorghum loose fill.

Palm leaves are the best choice for eco-friendly bio-based food packaging. Some brands that produce palm-based food packaging are Earth Cycle, Bio Futura and CaterEco. The leaves come from the Areca palm, which drops his leaves multiple times per year. These products do not contain a coating and can be composted after use. Its ease of decomposition as compost makes food packaging based on plant leaves have more value than other materials.

\section{DISCUSSION}

The AHP method reduced complex decision-making process to provide the result in this initial study. However, this initial study also had some limitations. The initial study was limited by the number of criteria and too many alternatives. Due to limited time to develop the framework, the study only able to setup general criteria. The fact that more specific criteria and sub-criteria maybe exist will change the results. Furthermore, despite the strengths of AHP, it was not dependable to evaluate a large number of judgements. Different knowledge from the expert also influences the selection process.

In order to develop more reliable result in the future, more novel and complex analysis is needed. Such methods by combining AHP with other DSS method will be beneficial for further research. More technical criteria and sub-criteria should be added, with regards to environmental friendly, cost material and quality criteria. Such additional factors could be used are price, technological maturity, raw material supply, application barriers and complementary technologies.

\section{CONCLUSION}

The new material for food packaging is highly potential to be developed from many alternatives. In order to determine the best material to be developed, 5 criterions and 13 alternatives were employed. AHP was helpful to select the material based on the setup criteria based on expert knowledge and experience. Given the criteria to select the best new alternative, we could select the best new material. The result shows that plant leaves material was the best material to be developed by the company or producers. The result from this initial study could be used for further framework development and novel approach. 
Vol. 47 Issue: 4, 2017. Permanent link to this document: http://dx.doi.org/10.1108/NFS-11-2016-0176.

[1] Tharanathan, R. "Biodegradable films and composite coatings: past, present and future." Trends in Food Science \& Technology, 14(3), 2003, pp 71-78. doi:10.1016/s0924-2244(02)00280-7.

[2] Singh P, Saengerlaub S, Wani A A, Langowski C H."Role of plastics additives for food packaging", Pigment \& Resin Technology, Vol. 41 Iss 6 , 2012, pp. 368 - 379 Permanent link to this document: http://dx.doi.org/10.1108/03699421211274306.

[3] Crevel R. Bio-based food packaging in Sustainable Development Challenges and opportunities to utilize biomass residues from agriculture and forestry as a feedstock for bio-based food packaging. Forest Products Team Forestry Policy and Resources Division, FAO, 2016.

[4] Kumar N, Kaur P, Bhatia S. "Advances in bio-nanocomposite materials for food packaging: a review", Nutrition \& Food Science,

[5] Han, J.-W., Ruiz-Garcia, L., Qian, J.-P., \& Yang, X.-T. Food Packaging: A Comprehensive Review and Future Trends. Comprehensive Reviews in Food Science and Food Safety, 17(4), 2018, pp 860- 877. doi:10.1111/1541-4337.12343.

[6] Saaty, T. L. How to Make a Decision: The Analytic Hierarchy Process. Interfaces, 24, 1994, pp 19-43. https://doi.org/10.1287/inte.24.6.19.

[7] Garlotta,, D.A. "Literature Review of Poly Lactic Acid". Journal of Polymers and the Environment, 9, 2001, pp 63-84.

[8] Dainelli, D., Gontard, N., Spyropoulos, D., Zondervan-van den Beuken, E., \& Tobback, P. Active and intelligent food packaging: Legal aspects and safety concerns. Trends in Food Science \& Technology, 19 (Suppl 1):S103-S112, 2008.

APPENDIX

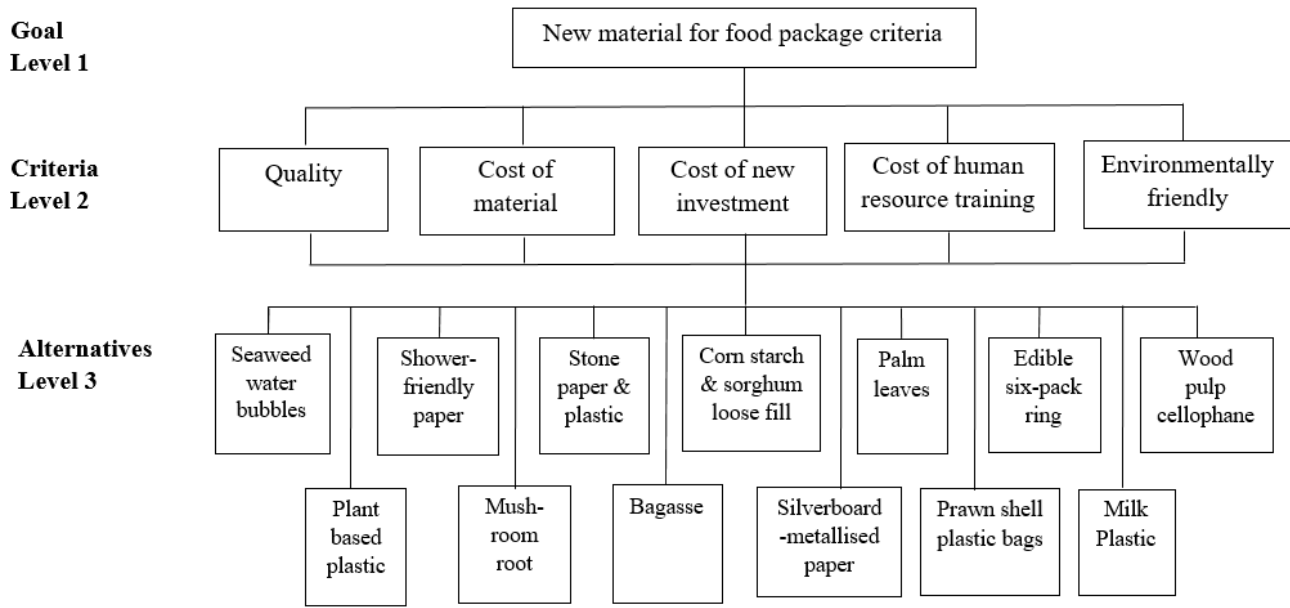

Fig 1. Hierarchy structure of AHP

Table 1 The AHP calculation and priority ranking

\begin{tabular}{lllll}
\hline Name & $\begin{array}{l}\text { Normalized } \\
\text { By Cluster }\end{array}$ & Limiting & $\begin{array}{l}\text { Priority } \\
\text { Ranking }\end{array}$ \\
\hline Goal & New Material For Food Package & 0.00000 & 0.000000 & \\
\hline Criteria & 0.21116 & 0.105582 & 3 \\
\hline & Quality & 0.23455 & 0.117277 & 2 \\
\hline Cost of Material & 0.13096 & 0.065479 & 4 \\
\hline Cost of New Investment & 0.10572 & 0.052860 & 5 \\
\hline Cost of human resource training & $\mathbf{0 . 3 1 7 6 0}$ & $\mathbf{0 . 1 5 8 8 0 2}$ & $\mathbf{1}$ \\
\hline Elternatives & Plant-based plastics & 0.10911 & 0.054555 & 2 \\
\hline Mushroom root & 0.09097 & 0.045484 & 6 \\
\hline Bagasse & 0.09550 & 0.047752 & 5 \\
\hline Seaweed water bubbles & 0.09670 & 0.048351 & 4 \\
\hline Shower-friendly paper & 0.07481 & 0.037405 & 7 \\
\hline Stone paper and plastic & 0.04082 & 0.020411 & 13 \\
\hline Corn starch and sorghum loose fill & 0.09939 & 0.049695 & 3 \\
\hline Palm leaves & $\mathbf{0 . 1 1 2 4 2}$ & $\mathbf{0 . 0 5 6 2 1 0}$ & $\mathbf{1}$ \\
\hline Edible six-pack ring & 0.06377 & 0.031883 & 8 \\
\hline Wood pulp cellophane & 0.06368 & 0.031840 & 9 \\
\hline Silber board - metallized paper & 0.04817 & 0.024085 & 12 \\
\hline Prawn shell plastic bags & 0.05498 & 0.027488 & 10 \\
\hline Milk plastic & 0.04968 & 0.024842 & 11 \\
\hline
\end{tabular}

Source: Primary Data Processed (2019) 